\title{
Research on Time-Temperature-Integrators of Meal-Ready-to-Eat Military Food Made by Thermo-sensitive Dyeing
}

\author{
B. Wang, J.-P. Yu, Z.-N. Ye, L.-L. Luo, F.-Y. Zheng \& J.-W. Jiang \\ Institute of Nutrition Food, Military School of Economics, Wuhan, Hubei, China
}

\begin{abstract}
Keywords: Time-Temperature-Integrators, Thermo-sensitive Dyeing
ABSTRACT: The quality of meal-ready-to-eat (MRE) military food was indicated. [Method] Based dyestuff 2-phenyl-3-methyl-6, 6-2 D-amino fluorane and 2, 2-bis (4-hydroxyphenyl) propane color developer thermo-sensitive system, time-temperature integrators (TTI) produced black by thermo-printer and faded gradually to show quality change of MRE military food. The timetemperature-optical density relational model of the TTI was compare with the time-temperatureacid value dynamics model of the food. it can match the time-temperature-optical density model of TTI to the time-temperature-acid value dynamics model of meal-ready-to-eat military food. The active energy of TTI's reaction is $74.1 \mathrm{~kJ} / \mathrm{mol}$ similar with $77.7 \mathrm{~kJ} / \mathrm{mol}$ of MRE military food`s reaction. The optical density of TTI`s standard camera is 0.8 compared with shelf life of MRE military food.
\end{abstract}

\section{INTRODUCTION}

Time-temperature integrators or indicator (TTI) can be defined as 'a small measuring device that shows a time-temperature dependent, easily, accurately and precisely measurable irreversible change that mimics the changes of a target attribute undergoing the same variable temperature exposure'. The major advantage of TTI is the ability to quantify the integrated time-temperature impact on a target attribute without information on the actual temperature history of the product. By the above definition, a TTI is clearly defined without any reference to knowledge on the timetemperature profile. The main kinetic criteria a system has to meet in order to be able to quantify the integrated thermal impact on a target attribute is that the temperature sensitivity of the rate constant (Ea value) of TTI and target attribute should be equal. A TTI based management system aiming to improve both quality and safety in the military food can be developed by applying the state of the art in TTI technology in conjunction with predictive models for chemical reaction and risk evaluation.

\section{MATERIALS AND METHODS}

\section{Materials}

2-phenyl-3-methyl-6, 6-2 D-amino fluorane (OBD-2), Kang'aite Weixun (penglai) Chemical Co., Ltd, without any treatment before use; 2, 2-bis (4-hydroxyphenyl) propane (BPA), Shanghai Haochem. Co., Ltd., without any treatment before use; PVA-205, Kuraray International Trading (Shanghai) Co., Ltd., Styrene butadiene latex, Shandong Zibo Longqi Chemical Co. Ltd., Calcined kaolin, Sensitizing agent BON, commercially available reagents. Individual self heating MRE military food was provided by Qinhuangdao Company.

\section{Instrument}

EDF-550 type multi functional lab dispersion machine, Shanghai Yile Electromechanical Equipment Co Ltd; X-Rite528 type optical density instrument, Shimadzu company in Japan.

5700FI-IR infrared spectrometer, America thermoelectric company Nicolet. Inova600 NMR, Varian products. DT-30B thermal analyzer, the Japanese production. 
Methods

Processing Methods

A certain amount of OBD-2 and water was added to multifunctional dispersion machine, grinded for 2 hours at the speed to 900r/min, then mixed with PVA-205 glue, grinded and dispersed for 15 minutes, prepared into solid content of glue $20 \%$.

BPA was grinded as the same way and mixed with OBD-2 glue, then coated on the base paper by a rod wrapped around with a wire. The coating was $7 \sim 9 \mathrm{~g} / \mathrm{m}^{2}$ by weight and placed in the kitchen ventilation drying at room temperature. The TTI paper changed into black as indicating color by a thermal printer and used to indicate the quality of the MRE military food.

Structure determination

Infrared analysis, pressed with potassium bromide; Nuclear magnetic resonance hydrogen spectrum, TMS as internal standard, the solvent is $\mathrm{CDCl}_{3}$.

Time-temperature-optical density (OD value) curve

The average values of TTI optical density was calculated by measured 10 times each time with XRite 528 at different temperature and different time.

Time-temperature-acid value curve

At different temperatures and different times, acid value was determined in accelerated aging tests. The time-temperature-acid value kinetics model was determined according to Arrhenius equation of regression analysis by excel and SPSS17.0 software.

\section{Matching method}

Arrhenius equation provides the theoretical basis for time-temperature-integrators for protection of food quality. When active energy $\mathrm{E}_{\mathrm{A}}$ and pre-exponential factor $\mathrm{k}_{\mathrm{A}}$ of food change are close to those of TTI's reaction, the TTI can be used for indication of food quality. The TTI is pasted on food packaging in order to undergoing the same temperature.

\section{RESULTS AND DISCUSSION}

\section{Structure analysis}

IR of 2-phenyl-3-methyl-6, 6-2 D-amino fluorane and BPA reaction product: $3303.4(\mathrm{~N}-\mathrm{H}), 3062.5$, 3023.9, 3000 2800 (C-H), 3000 2500, 1870 1650 (C=O carboxylic acid), 1600 1500 (C=C aromatic ring), 1300 1000 (C-O-C), 1000 650 (N-H), 800 650 (C-H). CNMR $\left(\mathrm{CDCl}_{3}\right): 14.510$ (alkyl), $29.570\left(-\mathrm{C}\left(\mathrm{CH}_{3}\right)_{3}\right), 50.611(\mathrm{C}-\mathrm{N}), 115.256,141.756$ (aromatic ring). At $150-170^{\circ} \mathrm{C}$, the molecular ion peak in mass spectrum of the black product is observed. 2D NMR of the product also proves the chromogenic reaction is as Scheme 1.

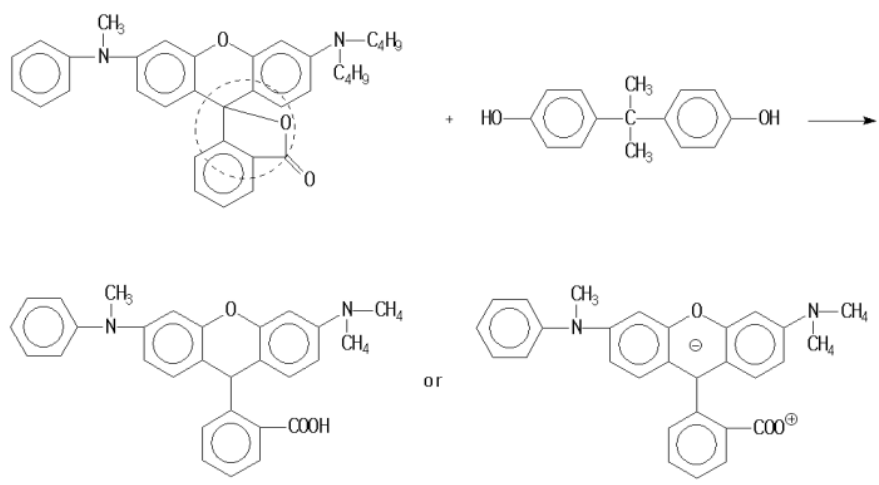

Scheme 1 


\section{Thermal analysis}

The components of TTI melt at $125^{\circ} \mathrm{C}$ and decompose at $300^{\circ} \mathrm{C}$ and weight loss rapidly. Therefore, the temperature of thermal printing is above $125^{\circ} \mathrm{C}$. Encapsulating temperature of the TTI should be lower than $125^{\circ} \mathrm{C}$, so as not to interfere with the discoloration reaction time of the TTI.

\section{Kinetic model for the military food}

The kinetics parameters of MRE military food are shown in table 1.

Table 1 Kinetic parameters for the growth rate of acid value on vacuum packed MRE military food.

\begin{tabular}{ccccc}
\hline $\mathrm{T}(\mathrm{K})$ & Model & $\mathrm{R}^{2}$ & $\mathrm{~K}$ & $\mathrm{~A}_{0}$ \\
\hline 311 & $A=2.0651 e^{0.0029 t}$ & 0.993 & 0.0029 & 2.065 \\
321 & $A=1.9888 e^{0.0073 t}$ & 0.999 & 0.0073 & 1.988 \\
331 & $A=1.992 e^{0.0178 t}$ & 0.997 & 0.0178 & 1.992 \\
\hline
\end{tabular}

The activation energy $\mathrm{E}_{\mathrm{A}}$ is $77.7 \mathrm{~kJ} / \mathrm{mol}$ by the processing of SPSS17.0, the pre exponential factor $\mathrm{K}_{\mathrm{a}}$ is $3.21 \times 10^{10} \mathrm{~h}^{-1}$. Therefore, Arrhenius equation for the acid value can be expressed as Eq. 1 .

$$
k_{a}=k_{a 0} e^{-\frac{E_{A}}{R T}}=3.21 \times 10^{10} e^{-77.71 \times 1000 / R T}
$$

The kinetic model for the MRE military food acid value can be expressed as Eq. 2.

$$
A=A_{0} e^{k_{a} t}=A_{0} e^{k_{a 0} e^{-E_{a} / R T} t}=2.00 e^{\left(3.21 \times 10^{10} e^{-77.71 \times 1000 / R T}\right) t}
$$

\section{Time-temperature-integrators model}

The kinetics parameters of GH-1TTI are shown in table 2.

Table 2 Kinetics parameters for the decrease rate of OD on TTI.

\begin{tabular}{ccccc}
\hline $\mathrm{T}(\mathrm{K})$ & Model & $\mathrm{R}^{2}$ & $\mathrm{k}$ & $\mathrm{A}_{0}$ \\
\hline 321 & $A=1.3707 e^{-0.0021 t}$ & 0.951 & 0.0021 & 1.370 \\
331 & $A=1.3711 e^{-0.0072 t}$ & 0.931 & 0.0072 & 1.371 \\
341 & $A=1.2559 e^{-0.0129 t}$ & 0.926 & 0.0129 & 1.256 \\
\hline
\end{tabular}

The activation energy $\mathrm{E}_{\mathrm{A}}$ is $83.0 \mathrm{~kJ} / \mathrm{mol}$ by the SPSS17.0 processing. The pre exponential factor $\mathrm{K}_{\mathrm{a}}$ is $7.17 \times 10^{10} \mathrm{~h}^{-1}$. Therefore, Arrhenius equation for the GH-1 TTI can be expressed as Eq. 3 .

$$
k_{a}=k_{a 0} e^{-\frac{E_{A}}{R T}}=7.17 \times 10^{10} e^{-82.95 \times 1000 / R T}
$$

The kinetic model for the GH-1TTI`s OD can be expressed as Eq. 4.

$$
A=A_{0} e^{k_{a} t}=A_{0} e^{k_{a 0} e^{-E_{a} / R T} t}=1.41 e^{-\left(7.17 \times 10^{10} e^{-82.95 \times 1000 / R T}\right) \mathrm{t}}
$$




\section{Matching}

The dynamics model of different TTI formula was determined shown in Table 3.

Table 3 Arrhenius equation for the decrease rate of OD on different TTI.

\begin{tabular}{ccc}
\hline TTI & Time-temperature-OD model & $\mathrm{E}_{\mathrm{A}}(\mathrm{kJ} / \mathrm{mol})$ \\
\hline ZK-N & $A=1.86 e^{-\left(6.24 \times 10^{9} e^{-7.12 \times 1000 / R T}\right) \mathrm{t}}$ & 74.1 \\
ZK-E & $A=1.46 e^{-\left(3.15 \times 10^{11} e^{-86.33 \times 1000 / R T}\right) \mathrm{t}}$ & 86.3 \\
GH-1 & $A=1.41 e^{-\left(7.17 \times 10^{10} e^{-82.95 \times 100 / R T}\right) \mathrm{t}}$ & 83.0 \\
GH-2 & $A=1.15 e^{-\left(5.15 \times 10^{14} e^{-107.38 \times 1000 / R T}\right) \mathrm{t}}$ & 107 \\
$\mathrm{GH}-3$ & $A=1.48 e^{-\left(3.27 \times 10^{8} e^{-67.72 \times 100 / R T}\right) \mathrm{t}}$ & 102 \\
\hline
\end{tabular}

The activation energy of MRE military food is close to that of ZK-N formula TTI by comparison of MRE military food kinetics model and the TTI dynamics model. ZK-N formula TTI can indicate the quality of MRE military food. The shelf life of the MRE military food is 1063 days at $25^{\circ} \mathrm{C}$, the standard color OD of ZK-N formula TTI is 0.8 accordingly. The standard color is printed by common black printing ink.

\section{CONCLUSIONS}

The time-temperature-optical density model of thermo-sensitive paper and the time-temperatureacid value model of meal-ready-to-eat military food are based on Arrhenius equation. By regulating the process and components of thermo-sensitive paper, it can match the time-temperature-optical density model to the time-temperature-acid value model of meal-ready-to-eat military food. The active energy of TTI and MRE military food are 74.1 and $77.7 \mathrm{~kJ} / \mathrm{mol}$. The standard OD of TTI is 0.8 compared with shelf life of MRE military food.

\section{REFERENCES}

1. Van BOEKEL, A. J. S. M. (2008) Kinetic modeling of food quality: a critical review.Comprehensive Reviews in Food Science And Food Safety, 7, 144-158.

2. Wright, B. B. (2004) U. S. Patent 6, 737, 274.

3. Wang, B. (2005) Synthesis and Oligomerization of Trans-N-3-yne-butenylcarbazole. Chin. J. Org. Chem. 25, 81-85 (In Chinese).

4. Corradini, M. G., Peleg, M. (2007) Shelf-life estimation from accelerated storage data. Trends in Food Science and Technology, 18, 37-47.

5. Giannakourou, M. C., Koutsoumanis, K., Nychas, G. J. E., et al. (2005) Field evaluation of the application of time temperature integrators for monitoring fish quality in the chill chain. International Journal of Food Microbiology, 102, 323-336. 